\title{
OS ANIMAIS PERFORMÁTICOS DE BEUYS, SHERK, BERWICK E DION
}

\section{Ana Carolina Cernicchiaro ${ }^{1}$}

\begin{abstract}
Resumo: Nas performances animais de Joseph Beuys, Bonnie Sherk, Rachel Berwick e Mark Dion, o ponto de vista irredutivel da alteridade inumana funda novos modos estéticos e éticos que colocam em questão as dicotomias ocidentais entre sujeito da arte e objeto de arte, mas também entre natureza e cultura, humano e inumano, mesmidade e alteridade.
\end{abstract}

Palavras-chave: Arte e animalidade. Joseph Beuys. Bonnie Sherk. Mark Dion. Rachel Berwick

Num sábado de fevereiro de 1970, ao almoçar trancafiada em uma das jaulas da área de alimentação dos felinos (enquanto os outros animais comiam nos covis ao lado), Bonnie Sherk se apresenta diante do olhar desestabilizador do animal. Na performance intitulada Public Lunch, a artista estadunidense colocava em cheque a ideia tradicional de objeto, tanto de objeto de arte quanto de objeto de conhecimento ou de entretenimento, tornando-se, ela própria, um animal/objeto enjaulado aos olhos dos visitantes do zoológico de San Francisco. Sherk está sujeita ao olhar do espectador, mas também ao olhar do animal, de forma que, a própria artista plástica confessa, Public Lunch resultou numa experiência profunda para pensar o potencial de percepção, inteligência e comunicação das outras espécies, para pensar o olhar do animal sobre o humano, para se sentir olhado pelo outro, para se ver sob o olhar do outro, sob o ponto de vista inumano.

\begin{abstract}
Public Lunch foi um trabalho seminal para mim. Durante a performance, eu andei, comi minha comida humana, subi até a plataforma, escrevi o que eu estava pensando e sentindo, deitei, descansei. Enquanto eu estava olhando o lindo céu sobre mim, vendo as nuvens e os pássaros acima, o tigre na jaula ao lado, sentou e ronronou para mim. Eu pensei, "este tigre está me percebendo; ele está me olhando. O que ele está olhando? O que ele está pensando? O que ele está sentindo? (SHERK, 2012) ${ }^{2}$.
\end{abstract}

As reações do tigre marcaram profundamente o trabalho performático de Sherk, que passou a incluir em suas pesquisas e performances o comportamento de outros animais. Mais do que um trabalho de etologia, do que um estudo de comportamento animal, tratava-se de um trabalho de performance: "The animals were performers, as was I" (SHERK, 2000). Mesmo antes de Public Lunch, Sherk já vinha desafiando as convenções de apresentação da arte e os limites usuais da galeria ao tentar trazer a experiência da natureza para a cidade com intervenções inesperadas, como a série Portable Parks, em que ela e Howard Levine expuseram palmeiras, mesas de picnic e

\footnotetext{
${ }^{1}$ Doutora em Literatura pela Universidade Federal de Santa Catarina. Atualmente, realiza estágio pósdoutoral na Universidade do Sul de Santa Catarina.

${ }^{2}$ Tradução minha.
} 
animais da fazenda e do zoo nas ruas de San Francisco. Esse trabalho levou Sherk ao projeto The Crossroads Community (também chamado de The Farm), que durou de 1974 a 1980. Construído sob uma movimentadíssima freeway de San Francisco, essa sorte de jardim ecológico, de "escultura performática ambiental", para usar uma expressão da própria Sherk, incluía, entre outras coisas, um teatro, um espaço para diferentes formas de arte, uma escola sem muros e uma biblioteca. Integrando todos estes elementos, Sherk se propunha a passar adiante aquilo que experienciou através da arte e da observação dos processos naturais, ou seja, "a interconectividade de diferentes estados de ser/conhecer/amar". Interconectividade esta que, acredita ela, pode ser a fonte para a emergência de novas formas de arte. Afinal, se, como afirma Hélio Oiticica, a arte é a formulação de novas possibilidades de vida ${ }^{3}$, também pensar outras formas de vida é possibilitar a irrupção de novas formas de arte. Uma espécie de "complexo de tostines" que vincula arte e mundo numa relação ética singularmente plural. Nas palavras de Sherk, "como artista, eu tentei expandir o conceito de arte para incluir, e até ser, a vida, e fazer visível as conexões entre diferentes sistemas de conhecimento" (SHERK, 2007, p. 227) ${ }^{4}$, a arte como um tríptico entre humano, animal e vegetal, como uma convergência global.

Outra prática artística que também é marcada por esta crença na capacidade ou potência da arte em reunir homem e natureza na construção de um novo mundo é a de Joseph Beuys, que inspirou boa parte dos artistas performáticos da segunda metade do século XX. Fundador de um partido político dos animais, Beuys acreditava que, uma vez que a atividade artística é capaz de produzir percepções mais profundas de experiência e estabelecer novas causas que podem mudar nossa maneira de se relacionar com a natureza, uma ideia real de ecologia somente poderia ser atingida pela arte.

É importante lembrar, no entanto, o caráter universal do conceito de arte de Beuys. Para ele, todo homem - ou mais que isso, todos os seres vivos - são artistas e podem desenvolver sua criatividade de maneira a transformar o mundo. Aliás, segundo ele, o homem só está verdadeiramente vivo quando realiza esse seu ser criativo, artístico, em todos os aspectos de sua vida. É preciso, no entanto, criar uma nova base para arte, porque esta que temos se tornou terrivelmente restrita no decorrer dos últimos cem anos. "Ela se tornou um território de poucos intelectuais, muito distante da vida das pessoas" $^{5}$, afirma Beuys (1997, p. 24), acrescentando que mesmo o ato de descascar uma batata pode ser uma obra de arte se for um ato consciente (BEUYS, 1990, p. 87).

Beuys defendia que a arte é o real capital de uma sociedade, a força revolucionária capaz de transformar a terra, a humanidade, a ordem social e etc (BEUYS, 1996, p. 30). Daí que suas performances sejam chamadas de "esculturas sociais", uma vez que funcionam como formas de moldar o mundo em que vivemos.

Meus objetos devem ser vistos como estimulantes para a transformação da idéia de escultura... ou da arte em geral. Eles podem provocar pensamentos sobre o que a escultura

\footnotetext{
3 “A fundação de uma obra não é a produção infinita do objeto: é a formulação de uma possibilidade de vida" (OITICICA, 2010).

${ }^{4}$ Tradução minha.

${ }^{5}$ Tradução minha.
} 
pode ser e como o conceito de escultura pode ser estendido para materiais invisíveis usados por todos.

FORMAS PENSADAS - como moldamos nossos pensamentos ou

FORMAS FALADAS - como moldamos nossos pensamentos em palavras ou ESCULTURA SOCIAL - como moldamos e damos forma ao mundo no qual vivemos: ESCULTURA COMO PROCESSO EVOLUCIONÁRIO; TODO MUNDO UM ARTISTA (BEUYS, 1990, p. 19) ${ }^{6}$.

Nessas esculturas sociais, como tentativas de interação entre o mundo humano e inumano, Beuys explicou arte para uma lebre morta, dividiu o palco com um cavalo branco, passou três dias num quarto com um coiote e plantou árvores, muitas árvores. Em um projeto concebido para a Documenta 7, em 1982, por exemplo, Beuys plantou sete mil carvalhos na cidade alemã de Kassel. O projeto apresentava um processo de revitalização não apenas da natureza, mas do organismo social como um todo, uma forma de resistência ao enorme processo letal que a humanidade causou através de seu conceito de materialismo e de seus processos de produção. A ideia era apontar para a importância de uma nova consciência, questionar o que exatamente é o homem e o que ele tem em comum com outros seres, despertar uma política sócio-ecológica, que permitisse entender o relacionamento entre humanidade e natureza como uma unidade, de maneira que, juntos, homem e natureza pudessem construir um novo mundo (BEUYS, 1996, p. 30). Para Beuys, a natureza é um lugar de eventos sociais. Como um diplomata cosmopolítico, como um xamã, ele pretendia religar o homem à terra, à natureza, aos animais, mostrar que o ser humano é um ser-com (com hífen, conforme a lição de Jean-Luc Nancy) com a natureza e que a árvore está tão ciente de nós quanto nós dela.

É isso que vemos em performances como Coyote: I Like America and America Likes Me. Em maio de 1974, Beuys foi pego por uma ambulância no aeroporto de Nova York e levado até a galeria René Block, onde dividiu um quarto com um coiote selvagem por uma semana. Embrulhado em um fino cobertor de feltro, às vezes apoiado em um cajado como um pastor, noutras caído como um objeto vulnerável diante do coiote (pastor mas também cordeiro), Beuys tentava estabelecer uma relação não hierárquica com o animal.

Little John, o coiote, cautelosamente rodeou Beuys, urinou sobre as cinquenta cópias do Wall Street Journal espalhadas pelo chão e trocou seu feno pelo cobertor de feltro de Beuys, que foi destruído em seguida. Ao final da experiência, Beuys é novamente embrulhado e levado ao aeroporto por uma ambulância, deixando a América sem ver nada além de um coiote: "Eu queria me concentrar somente no coiote. Eu não queria ver nada da América além do coiote" (BEUYS, 2008, p. 15) ${ }^{7}$. Conforme explica o próprio Beuys, a ideia era curar, como um xamã, um ponto psicologicamente traumático dos Estados Unidos com o povo nativo: "todo o trauma americano com o

\footnotetext{
${ }^{6}$ Tradução minha.

${ }^{7}$ Tradução minha.
} 
indígena, o Pele Vermelha. Você pode dizer que um acerto de contas foi feito com o coiote, somente assim esse trauma pode ser superado" (BEUYS, 1990, p. 141) ${ }^{8}$.

Mas por que o coiote? Como nos mostra Lévi-Strauss em História de lince (1993), o coiote é personagem constante nos mitos dos povos da América do Norte, seja como figura poderosa, heróica, ou como um malandro trapaceiro, um trickster. De um jeito ou de outro (como herói ou anti-herói), a escolha de Beuys pelo coiote não é gratuita. Os Estados Unidos que ele quer ter contato é os Estados Unidos capaz de ter um diálogo com o coiote, de devir-coiote. Assim como em "Meu tio o Iauaretê", de João Guimarães Rosa (2001), o devir-tupi implica um devir-onça e vice-versa ${ }^{9}$; também o devir-índio norte-americano implica uma relação de contágio com o coiote, um devircoiote, na medida que rememora uma relação perdida do homem com o animal, uma filosofia ou uma ontologia perspectivista, onde a subjetividade, a alma, o ponto de vista são potencialidades dos animais ${ }^{10}$. "Eu queria lembrá-lo que os seres humanos estão agora falando com ele. (...) que ele é compreendido como ator considerável na produção de liberdade, que nós precisamos dele como um produtor e um auxiliar importante" (BEUYS apud TISDALL, 2008, p. 14) ${ }^{11}$.

Segundo a análise da fotógrafa da performance, Caroline Tisdall, a chave para Coyote está no princípio de transformação: transformação da ideia de liberdade, transformação da linguagem, transformação do diálogo verbal em diálogo de energias (TISDALL, 2008, p. 12); transformação dos conceitos estanques ocidentais em fluidez perspectivista, poderíamos acrescentar. Tisdall percebeu que, ao interagir com o coiote,

\footnotetext{
${ }^{8}$ Tradução minha.

${ }^{9}$ A leitura proposta aqui vê na onça algo mais do que uma representação totêmica clássica, vê um deviríndio-onça e um devir-onça-índio. Um devir-onça que é um devir-índio do sertanejo, uma jaguaridade potencial (xamânica ou canibal) do índio, como forma ideal de predação, de devoração do outro e de seu ponto-de-vista. Essa vontade de devorar o ponto de vista do outro, o desejo de ser o outro, a incorporação do outro, a saída de si é o que faz do modo de ser indígena um modo de devir-outro, pois a relação com o outro funda a identidade, da mesma maneira que a relação com o inimigo funda a sociedade. Por outro lado, tal devir-onça pressupõe uma potencialidade canibal (humana) do jaguar, uma capacidade de assumir a posição reflexiva, de ser sujeito, de não domesticação ou coisificação do inumano. O sobrinho do Iauaretê se torna índio e onça, pois as duas coisas estão interligadas como duas faces da mesma moeda: ao assumir sua cultura indígena, ele assume também a proximidade dessa cultura com a natureza, seu pensamento não dicotômico, que vê natureza e cultura como séries contínuas e não como dois domínios ontológicos diferentes, estanques. Um pensamento que propõe uma diferença relativa, mesurável e flexível, ou melhor, um estado de diferenciação permanente, um modo de ser que é um modo de devir.

10 Desenvolvido por Eduardo Viveiros de Castro em parceria com Tânia Stolze Lima a partir das concepções indígenas (em especial das tribos de origem tupi-guarani) de mundo, pessoa, sujeito, humano e não-humano, o perspectivismo multinaturalista se refere a um aspecto do pensamento ameríndio que define que "o mundo é habitado por diferentes espécies de sujeitos ou pessoas, humanas e não-humanas, que o apreendem segundo pontos de vista distintos" (VIVEIROS DE CASTRO, 2002, p. 347). Para esta cosmologia, a consciência e a cultura, a subjetividade e a intencionalidade não são exclusividade dos humanos, mas potencialidades de uma infinidade de outras espécies. Cada uma das diferentes formas de vida vê sua própria espécie como humana, considerando as outras como animais ou espíritos. Isso porque, para o pensamento perspectivista, a forma manifesta de cada espécie seria um envoltório, uma roupa, que esconde a forma interna humana (a forma mítica original de todos os seres) e que é visível apenas aos olhos da própria espécie ou "de certos seres transespecíficos, como os xamãs" (VIVEIROS DE CASTRO, 2002, p. 351).

${ }^{11}$ Tradução minha.
} 
Beuys está se relacionando com uma outra América, daí o título irônico I Like America and America Likes Me, justamente porque a América que ele gosta e que gosta dele, é outra, é a do coiote, uma América que pressupõe uma outra relação com a natureza e com os animais, uma América que percebe os animais como seres capazes de um embate ético. E é a essa América que Beuys quer se abrir para escutar a voz; principalmente porque, para Beuys, essa é a responsabilidade de todo ser humano em relação aos outros seres: ouvir a voz do mundo mudo.

Assumir tal responsabilidade é o que, dez anos antes, já havia levado Beuys à performance The Chief (1963-64). Num quarto com esculturas de gordura nos cantos, Beuys, enrolado em uma manta de feltro, mas dessa vez com uma lebre morta em cada ponta do tecido, fazia barulhos incompreensíveis que eram amplificados no quarto e na rua. Continuando essa ideia, no ano seguinte, em How to Explain Pictures to a Dead Hare, a proposta era, mais uma vez através da lebre, entrar no mundo animal e vegetal que é parte de nós, parecer uma lebre, devir-lebre: "Eu não sou um ser humano, na realidade eu sou uma lebre. Isso é muito real. Eu trabalho com esta transformação" (BEUYS, 1997, p. 14) ${ }^{12}$.

A famosa performance acontecia em uma galeria fechada, que permitia ao público apenas espiar pela janela. Com a cabeça coberta de mel e de folhas douradas, Beuys fazia a pata da lebre tocar os quadros e sussurrava em sua orelha explicações sobre cada um deles. Depois de finalizar o tour, o artista sentou em uma cadeira e começou a explicar os quadros a sua pequena amiga, afinal, conclui ele, "eu acho que hoje é melhor explicar a importância da arte aos animais do que aos seres humanos" (BEUYS, 1997, p. 9) ${ }^{13}$. Para ele, a lebre, assim como uma oliveira, um cipreste, um cavalo, o mar, as montanhas são partes do interior do homem, são órgãos do homem da mesma maneira que o fígado, o coração, os rins e todo o resto, e se formos capazes de explicar pinturas para esse órgão externo, então a arte poderá ser entendida como uma genuína ratificação dos poderes criativos do homem (BEUYS, 1996, p. 30). Beuys defende que a arte é algo que desafia nossa vontade de síntese, de representação, de sentido único, de explicação, de entendimento. De maneira tal que mesmo uma lebre morta possui mais intuição do que um ser humano cuja racionalidade se tornou inflexível, cujo pensamento foi intelectualizado até um nível mortífero:

Em nossos tempos, pensar se tornou algo tão positivista que as pessoas só apreciam o que pode ser controlado pela razão, o que pode ser útil, o que alavancar sua carreira. Por isso eu sinto que é necessário apresentar algo mais do que meros objetos. Ao fazer isso, quem sabe as pessoas possam começar a entender que o homem não é só um ser racional (BEUYS, 1990$, p. 86) $)^{14}$.

Beuys olhou o coiote e se viu olhado pelo animal, falou e ouviu a lebre. Ele se entregou aos olhos do animal para se tornar uma espécie de objeto, uma escultura em que os espectadores não são os visitantes que espiam de fora da galeria, mas o próprio

\footnotetext{
12 Tradução minha.

13 Tradução minha.

${ }^{14}$ Tradução minha.
} 
coiote, a própria lebre. Tal questionamento sobre as fronteiras do humano e do animal se confunde com uma pergunta sobre os papéis (e os limites desses papéis) do espectador, do artista, do sujeito da arte, e do objeto de arte, da coisa que se contempla. Conforme analisou Valerie Casey, How to Explain Pictures to a Dead Hare critica as relações pré-concebidas entre espectadores e objetos na indústria da arte, especialmente na galeria e no museu, desafiando as interpretações e apropriações super racionalizadas do mundo da arte (CASEY, 2005).

É esse tipo de crítica que vemos também na série The Library for the Birds, de Mark Dion, apresentada em Massachusetts, Nova York e Antuérpia. A primeira delas, The Library for the Birds of Antwerp, de 1993, foi exibida no Museum van Hedendaagse Kunst da Antuérpia e contava com 18 pássaros que voavam, empoleiravam-se e cantavam sobre uma árvore que marcava o centro da instalação (a biblioteca dos pássaros). Os pássaros, totalmente livres, fizeram do ambiente sua casa graças a um jogo de luzes que os atraía. Os objetos que os circundavam, gaiolas de madeira da África e da América, lembravam o mercado lucrativo de pássaros exóticos que começou no século XVI e continua até hoje no Vogelmarkt de Antuérpia, onde as aves foram compradas. Além das gaiolas, de uma reprodução de Concerto das Aves, do flamengo Frans Snyders, de retratos de pássaros e de uma foto do aviário do zoológico da Antuérpia, os sinais de captura e extinção estavam em todos os lugares, nos livros expostos sobre a árvore, em ilustrações e, principalmente, na árvore seca no centro da instalação. Como se a biblioteca rememorasse uma história dos vencidos, da presa, do animal em extinção, contra a história oficial do desenvolvimentismo.

Aliás, os animais em extinção são um tema recorrente nas obras de Mark Dion. Em Tar and Feathers, de 1996, por exemplo, animais taxidermizados pendurados numa macabra árvore coberta de alcatrão (tar) e penas (feather) chamam a atenção para este problema. O próprio nome/material da instalação já remete à crueldade da relação do homem com o inumano (no caso, com o homem inumanizado), já que lembra uma prática de punição, tortura e linchamento dos tempos feudais que persistiu nos Estados Unidos e na Inglaterra ainda no século XX. Impossível também não lembrar da famosa cena da Guerra do Golfo em que pássaros cobertos de petróleo agonizavam diante das câmeras. De uma maneira ou de outra, permanece o elemento macabro, aterrorizador, que, segundo o próprio Dion, tem a ver com a temática da extinção. "Eu acho que quando se lida com questões como extinção, é difícil não se tornar um pouco macabro" (DION, 1997, p. 33) ${ }^{15}$.

Também neste sentido, vale uma referência a May-por-é, de Rachel Berwick. O trabalho de 1997 (que esteve em Porto Alegre para a Bienal do Mercosul de 2004), consiste num aviário escultural com dois papagaios amazônicos que falam uma língua indígena extinta. As aves foram ensinadas por ela a partir das anotações de Alexander Von Humboldt, que, em 1799, adquiriu um dos papagaios que haviam sido domesticados por uma tribo indígena caribenha já dizimada e que eram os únicos "falantes" da língua Maypure. As paredes translucidas do aviário ao mesmo tempo que encobrem os papagaios (apenas suas sombras podem ser vistas pelo espectador),

\footnotetext{
${ }^{15}$ Tradução minha.
} 
também remetem à ideia de rastro, de vestígio, de traço, como se um rastro do humano extinto perdurasse no animal - aquele que é tradicionalmente o extinto -, mais ironicamente ainda, na linguagem deste animal - justamente aquela característica considerada exclusiva do homem, responsável até por separá-lo dos outros viventes ${ }^{16}$.

Da mesma maneira que os papagaios de Berwick colocam em questão a diferença entre natureza e cultura ao testemunhar a extinção de um povo e sua língua; os pássaros de Mark Dion, ao ganharem uma biblioteca num espaço institucional como o museu de arte, revelam-se seres mais do que naturais. Ao mesmo tempo, seus espectadores humanos, ao entrarem no espaço dos pássaros e serem sobrevoados por eles, também não são mais seres puramente culturais. Ali, homens e pássaros são intersecções de arte e espectador, sujeito e objeto, natureza e cultura ${ }^{17}$.

Norman Bryson mostra que Dion está interessado na interface entre a natureza e a história das disciplinas e dos sistemas de poder que a tomam como seu objeto de conhecimento, que a classificam e a controlam. Daí, afirma Bryson, o caráter paradoxal de uma biblioteca para pássaros, pois, se todo saber sobre o mundo natural é condicionado pelas instituições de conhecimento, com sua maneira própria e particular de produção da verdade, então o real, a natureza, não é tanto o que aparece mas o que permanece à margem da representação (BRYSON, 1997, p. 96), aquilo que pode ser invocado pela experiência do espectador, devido justamente à proximidade (confusão, podemos dizer) entre o sujeito e o objeto de arte.

Para além de suas bibliotecas para pássaros, toda obra de Mark Dion traz uma preocupação com os limites entre natureza e cultura e suas instituições colecionadoras. Ao investigar o museu de arte, o museu de história natural, o zoológico e os elementos de dominação que os envolvem, ele mostra de que maneira esses espaços dividem, além de sua descendência em comum, um mesmo objetivo: exibir tesouros e troféus, de modo a ostentar o poder, a influência e o conhecimento do proprietário de tais coleções, seja este um indivíduo ou uma nação. Não é a toa que a nacionalização e a abertura à visitação pública dos zoológicos e dos museus se deu em conjunto nos séculos XVIII e XIX. Tanto quanto os zoos, os museus são coleções de perspectivas históricas na qual se constitui um conhecimento sobre o outro, dispositivos imperiais que representam um certo tipo de saber estatal objetivante sobre este outro, um indicativo da capacidade de classificá-lo, controlá-lo e dominá-1o ${ }^{18}$.

\footnotetext{
${ }^{16} \mathrm{O}$ tema também aparece em outra instalação de Rachel Berwick. Lonesome George, de 2005, fala de uma tartaruga de 80 anos que é - ou melhor, era (em junho deste ano, ouvi em algum noticiário estadunidense a notícia de sua morte) - a última de sua espécie. Neste trabalho, Berwick dramatiza este sentido de perda, com velas de embarcações que se enchem de ar toda vez que George aparece se recolhendo em seu casco no vídeo que compõe a instalação.

${ }^{17}$ Semelhante questão expôs Pauline Bastard em Campo contra campo, apresentado na $30^{\mathrm{a}}$ Bienal de São Paulo: A iminência das poéticas, em 2012. O vídeo de nove minutos filmado por dois cavalos videomakers, que possuíam uma câmera acoplada na cabeça, apresenta uma arte executada pelos próprios animais, que, além de revelar o olhar do animal e o mundo como visto por eles, ainda questiona os limites entre natureza e cultura, museu de arte e museu de história natural, ao expor este olhar e este mundo numa Bienal.

${ }^{18}$ Este outro pode ser animal, mas também humano. A última exposição de animais humanos enjaulados em zoológicos foi a de uma família do Congo, há pouco mais de 50 anos, em 1958, em Bruxelas. Entre os primeiros desses povos exóticos expostos na Europa estão a família de índios tupinambá que desfilaram,
} 
Os zoológicos públicos surgem quando os animais começam a desaparecer da vida cotidiana. Como afirma John Berger, o zoo é uma espécie de epitáfio de uma relação que era tão antiga quanto o homem e que se perdeu. $\mathrm{O}$ olhar entre o homem e o animal, que teve um papel crucial no desenvolvimento da sociedade humana e com o qual todos os homens conviveram, foi extinto. Por isso o zoológico - este "lugar de exclusão e reclusão dos animais selvagens" (SANTIAGO, 2006, p. 183) - não pode senão desapontar, pois em nenhum lugar do zoo se pode encontrar o olhar do animal: "O zoo ao qual as pessoas vão para encontrar o animal, para observá-los, para vê-los, é, de fato, um monumento à impossibilidade destes encontros" (BERGER, 1997, p. 103) ${ }^{19}$.

Ainda que, como disse Berger, o zoológico não seja um espaço propício para o encontro com o animal por ser um lugar de objetivação, dominação e classificação do outro, quando apropriado pela arte, ele pode, sim, revelar o olhar do animal sobre nós. A jaula de Bonnie Sherk, o viveiro dos papagaios de Rachel Berwick, a biblioteca para pássaros de Mark Dion, a galeria onde Joseph Beuys está preso com um coiote, são espaços que se parecem com o zoológico (no caso de Sherk é o próprio zoológico), mas que o inverte, o transforma. A arte abre as jaulas do zoológico, mas também do museu, na medida que confunde a separação entre homem e animal e entre arte e mundo, na medida que expõe não mais um animal objeto, um objeto espetacular, ou um homem animalizado, mas uma relação de devir.

Segundo Deleuze e Guattari, a arte não é um fim, mas um instrumento para traçar os devires, linhas de vida, fugas ativas. Fugas que não fazem da arte um refúgio, pois são "desterritorializações positivas, que não irão se reterritorializar na arte, mas que irão, sobretudo, arrastá-la consigo para as regiões do a-significante, do a-subjetivo e do sem-rosto" (DELEUZE; GUATTARI, 2008, p. 57). Trata-se de uma das funções políticas da arte, pois o devir nos libera, afirma Peter Pál Pelbart, da forma do "homembranco-macho-racional-europeu". Através dele, a arte abandona a "Forma-homem, ao embarcar em devires minoritários, inumanos, plurais", transpondo as fronteiras entre "o animal, o vegetal e o mineral, ou entre o humano e inumano, o individual e o coletivo, o masculino e o feminino, o material e o imaterial, etc" (PELBART, 2000, p. 69).

Como explica Nato Thompson, em "Monstruos Empathy" - texto de abertura ao catálogo da exposição Becoming-Animal, organizada pelo Massachusetts Museum of Contemporary Art (MASS MoCA), de maio de 2005 a março de 2006, que incluía trabalhos de Dion e Berwick -, quando Deleuze e Guattari desenvolvem esta ideia, desestabilizam as fronteiras restritas e arbitrárias da modernidade entre a humanidade e o reino animal. Segundo ele, o termo devir permite o intercâmbio entre concepções de mundo outrora estáticas como homem/natureza, homem/mulher, eu/nós, humano/animal (THOMPSON, 2005, p. 8), pois, no devir, não há divisões essenciais entre minerais, vegetais, animais e humanos, mas um contínuo, um campo de forças virtuais, intensidades e forças, que estão sempre mudando conforme se encontram e se relacionam com outras entidades.

\footnotetext{
em 1550, para o rei Henrique II e a nobreza em Rouen, na França. Mas foi no início do século XIX, que estas exposições se tornaram mais populares. Segundo Pascal Blanchard, mais de 1 bilhão de pessoas assistiram aos espetáculos de "humanos exóticos" realizados entre 1800 e 1958 (BLANCHARD, 2008).

${ }^{19}$ Tradução minha.
} 
Como todos os seres, o ser humano também está engajado nestas constantes relações de devir, que nos abrem a outros modos de existência. Daí Jacques Derrida concluir que o ponto de vista do animal sobre o humano traz questões que "engajam um pensamento do que quer dizer viver, falar, morrer, ser e mundo como ser-no-mundo ou ser-ao-mundo, ou ser-com" (DERRIDA, 2002, 29).

Esta citação de $O$ animal que logo sou nos remete ao pensamento de Jean-Luc Nancy, para quem o ser não é outra coisa senão o ser-uns-com-os-outros, circulando no com e pelo com da co-existência singularmente plural. Para o autor de Ser Singular Plural, o homem está no mundo porque o mundo é sua própria exterioridade, o mundo é o não-humano ao qual o humano se expõe. Por isso o homem não é o fim da natureza; seu fim, sua finalidade, é o ser-no-mundo e o ser-mundo de todo o existente.

Ao se colocar como campo aberto à alteridade, a arte deixa de ser uma apresentação do eu ou uma representação do outro e passa a ser uma presentificação de seres-uns-com-os-outros singularmente plurais. $\mathrm{O}$ mesmo se apaga porque justamente a partícula eu, que define e forma toda ipseidade, está tomada por um outro que não é identitário, não é fixo, mas que está sempre em devir. Assim é que, na arte que se expõe ao olhar do animal, na arte que se deixa atravessar por esse olhar, não há fixação do eu, mas ficção do eu, fricção do eu com muitas outras coisas que o contagiam, afetação infinita e múltipla, afinal, o ser nada mais é do que um ser-com, um ser-entre-muitosoutros, e de inúmeras espécies.

\section{REFERÊNCIAS}

BERGER, John. "Why look at animals?". In: CORRIN, Lisa Graziose; KWON, Miwon; BRYSON, Norman. Mark Dion. New York and London: Phaidon Press, 1997.

BEUYS, Joseph. "Interview with Richard Hamilton". In: BEUYS, Eva; BEUYS, Wenzel; BEUYS, Jessyka. Joseph Beuys - Block Beuys. München, Paris, London: Schirmer/Mosel, 1997.

"Introduction" (1979) e "Interview with Willoughby Sharp" (1969). BEUYS, Joseph. Energy

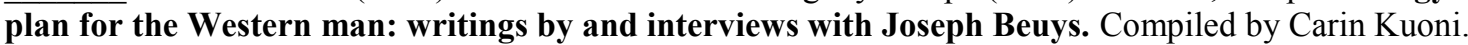
New York: Four Walls Eight Windows, 1990.

"Questions to Joseph Beuys. Interview by Jörg Schellmann and Bernd Klüser". In:

SCHELLMANN, Jörg (ed.) Joseph Beuys - The multiples. Cambridge, Minneapolis and München/New York: Busch Reisinger Museum, Walker Art Center, and Edition Schellmann, 1997.

BLANCHARD, Pascal. Human zoos: Science and Spectacle in the Age of Empire. Liverpool: Liverpool University Press, 2008.

BRYSON, Norman. "Mark Dion and the Birds of Antwerp". In: CORRIN, Lisa Graziose; KWON, Miwon; BRYSON, Norman. Mark Dion. New York and London: Phaidon Press, 1997.

CASEY, Valerie. "Staging Meaning - Performance in the Modern Museum". In: The Drama Review. v. 49, n. 3. New York: New York University and the Massachusetts Institute of Technology, 2005.

DELEUZE, Gilles; GUATTARI, Félix. Mil platôs: capitalismo e esquizofrenia. Vol. 3. Trad. Ana Lúcia de Oliveira e Lúcia Cláudia Leão. $4^{\mathrm{a}}$ reimpressão. São Paulo: Editora 34, 2008.

DERRIDA, Jacques. O animal que logo sou. Trad. Fábio Landa. São Paulo: Editora UNESP, 2002.

DION, Mark. "Miwon Kwon in conversation with Mark Dion". In: CORRIN, Lisa Graziose; KWON,

I Miwon; BRYSON, Norman. Mark Dion. New York and London: Phaidon Press, 1997.

DURINI, Lucrecia de Domizio. Difesa della Natura. Milano: Edizioni Charta, 1996.

LÉVI-STRAUSS, Claude. História de lince. Trad. Beatriz Perrone-Moisés. São Paulo: Companhia das Letras, 1993. 
NANCY, Jean-Luc. Ser singular plural. Trad. Antonio Tudela Sancho. Madrid: Arena Libros, 2006. OITICICA, Hélio. "Meu trabalho é subterrâneo" [atribuído]. Mar/1970. In: Programa Hélio Oiticica. Disponível em: <http://www.itaucultural.org.br/aplicexternas /enciclopedia/ho/home/index.cfm.> Acesso em: 15 jun 2010 .

PELBART, Peter Pál. A vertigem por um fio. Políticas da subjetividade contemporânea. São Paulo: Editora Iluminuras, 2000.

ROSA, João Guimarães. "Meu tio o Iauaretê". In: Estas Estórias. 5ª ed. Rio de Janeiro: Nova Fronteira, 2001.

SANTIAGO, Silviano. "Bestiário". In: SANTIAGO, Silviano. Ora (direis) puxar conversa! Belo Horizonte: Editora UFMG, 2006.

SHERK, Bonnie. A Living Library - Archive for the 'Art, Landscape Architecture, \& Systemic Design' Category. Disponível em: <http:/www.alivinglibrary.org/blog/ category/art-landscapearchitecture-systemic-design>. Acesso em: 20 jun 2012.

Interview. In: MONTANO, Linda (compilated by). Performance Artists Talking in the Eighties: Sex, Food, Money/Fame, Ritual/Death. Berkeley: University of California Press, 2000.

Position Paper on Crossroads Community (The Farm). Extract from a presentation at the First International Symposium of the Center for Critical Enquiry, San Francisco Art Institute, November 1977. In: BRADLEY, Will; ESCHE, Charles. Art and social change - a critical reader. London: Tate Publishing, 2007.

THOMPSON, Nato. "Monstruous Empathy". In: THOMPSON, Nato (ed.). Becoming Animal: Contemporary Art in the Animal Kingdom. Cambridge: MASS MoCA Publications, 2005. TISDALL, Caroline. Joseph Beuys - Coyote. London: Thames \& Hudson, 2008.

VIVEIROS DE CASTRO, Eduardo. A inconstância da alma selvagem e outros ensaios de antropologia. São Paulo: Cosac \& Naify, 2002.

Recebido em: 14/06/2014. Aprovado em 15/06/2014.

Title: Performing animals of Beuys, Sherk, Berwick and Dion

Author: Ana Carolina Cernicchiaro

Abstract: On Joseph Beuys, Bonnie Sherk, Rachel Berwick and Mark Dion animal performances, the irreductible point of view of inhuman alterity establishes new aesthetics and ethics modes that call into question the occidental dichotomies between subject and object of art, as well nature and culture, human and inhuman, selfness and otherness.

Keywords: Art and animality. Joseph Beuys. Bonnie Sherk. Mark Dion. Rachel Berwick. 